\title{
Risk analysis and vulnerability assessment in flood protection and river basin management
}

\author{
D. De Wrachien ${ }^{1}, \mathrm{~S}$. Mambretti ${ }^{2} \&$ A. Sole ${ }^{3}$ \\ ${ }^{1}$ Department of Agricoltural Hydraulics, State University of Milan, Italy \\ ${ }^{2}$ DIIAR, Politecnico di Milano, Italy \\ ${ }^{3}$ DIF A, Università degli Studi della Basilicata, Italy
}

\begin{abstract}
The water-related disasters are considerably increasing worldwide in the last years. While certain trends are global (like climate change), some actions to contrast these problems have to be taken locally. In any case, the land characteristics should be known and analyzed in order to contrast the hazards and avoid their transformations into damages or disasters when exceptional events occur.

This paper firstly presents preliminary definitions about the concepts of hazard, vulnerability, risk and damage/disaster, because there is a certain lack of uniformity in the use of terms, which sometime drives towards a confusion; thus definitions are offered, with a special attention paid to the flood problems. Then, risk analysis procedures are described, which consist of systematic actions in a cycle of preparedness, response and recovery, and should form part of the integrated water resources management. Moreover, the flooding problem characteristics and the policy and related measures adopted by different European countries, to protect themselves against floods, are considered and the lessons learnt from flood defence analyzed, with the aim of featuring a new integrated flood and management approach that allocates more space for rivers and keeps a balance between present and foreseeable future spatial requirements of both water and people.
\end{abstract}

Keywords: flooding, risk management, flood protection measures, integrated water management. 


\section{Introduction}

Floods are among the most damaging of natural hazards, and are likely to become more frequent, more prevalent and most serious in the future due to the effects of climate change and urbanization.

The nature and occurrence of floods are governed by diverse factors, including rainfall characteristics, properties of the drainage catchment and land and water use and management in the catchment.

The terms "flood" and "flooding" are often used in different ways. According to ICID [17] flood is "a temporary condition of surface water (river, lake, sea) in which the water level and/or discharge exceed a certain value, thereby escaping their normal confines". Flooding is defined "as the overflowing or failing of the normal confines of a river, stream, lake, canal, sea or accumulation of water as a result of heavy precipitation where drains are lacking or their discharge capacity is exceeded".

Although flooding is a serious hazard in humid regions, it can be devastating also in semiarid regions, where high rates of runoff following storms produce widespread flood damage down valley. Recurring floods are also typical in coastal and estuarine zones [21].

To cope with these hazards, it is imperative that human society adopts an effective flood hazard management approach which has to be in harmonious coexistence with floods. In practical terms, the chance of flooding can never be eliminated entirely. However, the consequences of flooding can be mitigated by appropriate behaviour and actions. To be effective, the hazard approach must be embodied in the broader context of integrated catchment planning, and flood must be regarded as one of the many issues involved in the appropriate management of a catchment [11].

In the paper, after a preliminary definition of the keywords used in the literature dealing with flood hazard assessment, the main features of the risk analysis and flood and river basin management processes will be outlined, along with the lessons learnt from experiences in flood mitigation and control in Europe.

\section{Preliminary definitions}

Before the description of a possible methodology to carry out risk analysis and its application to a number of case studies, it is necessary to provide some preliminary definitions, because of a certain lack of uniformity in the use of terms.

In the UNESCO report [20] hazard is defined as the "probability of occurrence of a potentially dangerous event in a fixed time range and in a fixed area". In this definition the concepts of time and space are explicitly stated, but the event magnitude concept is not mentioned. The Einstein approach is quite different [6]. The hazard concept definition is based on the geometrical and mechanical characteristics of the natural phenomenon. In this way the concepts 
of magnitude and area of potentially dangerous event are explicit and hazard is defined as the "probability of occurrence of a danger in a fixed time range".

In practice, hazard $H$ is described in different ways in relation with the topic/issue (earthquakes, landslides, debris flows, etc.) dealt with. The return period is often used in order to characterise the events with fixed magnitude in a specific area. To this regard, a relevant aspect ,neglected in Varnas' definition , is the spatial propagation of the phenomenon. If the propagation is neglected, the risk analysis results uncompleted, because it is limited to the beginning of the process. It is equally important, instead, the probability that the wave reaches at a certain time, a certain place. In this case it seems more appropriate to define it as induced hazard.

Exposition $E$ can be defined as the "probability that a certain element be exposed to the risk when an event of fixed magnitude, in a fixed time range and in a fixed area, occurs". Different Authors define $E$ as the "probability that an element be affected by a fixed hazard "Sometimes exposition is also defined as a "quantitative index to sum up the number of persons and goods potentially subject to the event".

Vulnerability $V$ can be defined as the inverse of the resilience, where resilience describes the capacity of ecosystems to react against the stress. Thus, vulnerability represents the territorial system tendency to suffer damages during an extreme event.

Risk $R$ is the total damage caused by a specific event, and it is obtained as a function of hazard, exposition and vulnerability: $R=H \cdot V \cdot E$.

According to the Swiss Civil Protection Agency, disaster is an event where damage exceeds the capacity of the affected society to recover by its own means. This definition is based on the economic capacity of the affected society, which means that the same event has different impacts depending on where it happens.

\section{Risk management}

Risk is an integral part of social and economic processes and is often increased by human interference with natural hydro-meteorological phenomena. The struggle against extreme events like floods and droughts is old as mankind. But in the last decades, new challenges are likely to influence risk management measures and policies. These challenges can be summarized as follows:

- climate change is likely to impact climate variability, making extreme events more severe and more frequent;

- $\quad$ increasing world population and economic growth lead to a more intense use of water and land resources;

- there is a rising awareness of the need of integrated water resources management, considering the river basin as the basic planning unit;

- due to the relentless urbanisation process, at worldwide level, hazards are increasingly transforming into disasters putting development at risk;

- there is a rising concern that damages resulting from water related disasters are growing disproportionately worldwide. 
To cope with these challenges involves taking decisions and actions about appropriate levels of risks. These decisions and actions may be divided into the following two processes:

1. risk analysis procedures;

2. risk management cycle.

\subsection{Risk analysis procedures}

In recent years risk analysis has emerged as one of the most appropriate methods nowadays available to assess natural hazards, like floods and other water related disasters. This methodology proved to be comparatively reliable in determining the hazard potential and the related probability of occurrence of defined extreme events, even if modelling approaches differ.

This process requires expert knowledge to identify the potential risks and then to estimate the likelihood and the impacts of these risks. Risk likelihood and risk impact comprise uncertainty. In this context, the last two decades have observed an amazing progress in the use of probability theory to assess uncertainty. Ang and Tang [1] assumed that the total uncertainty is an outcome of randomness and error on prediction. El-Cheikh et al. [7] stated that while previous researches have employed the Quantitative Risk Analysis (QRA) approach, they also have demonstrated the effectiveness of the probability theory and of other procedures, like Monte Carlo simulations and the fuzzy sets technique, in order to assess risks and to design a new risk analysis approach. These studies, however, do not tackle the logic behind the uncertain occurrence of the nominated risks, whether there is randomness behind the uncertainty or vagueness behind it.

In practice, the object of risk-analysis changes depending on both the hazard to be considered and the means or systems adopted to mitigate the damage. To this regards, floods are natural hazards which occur periodically and episodically and cannot be prevented.

Therefore, the responsible authorities in most European countries developed methods of integrated risk management, which follow, mainly, the systemengineering approach to express risk as a product of hazard and values at risks [7], according to equation (1):

$R=p_{S i} \cdot A_{O j} \cdot p_{O j, S i} \cdot v_{O j, S i}$

with $R$ : risk; $p_{S i}$ : probability of scenario $i ; A_{O j}$ : value at risk of object $j ; p_{O j, S i}$ : probability of exposure of object $j$ to scenario $i$; $v_{O j, S i}$ : vulnerability of object $j$, dependant on scenario $i$.

Following equation (1), it becomes apparent that all parameters have a linear influence on the result of risk analysis. The procedure of hazard assessment is methodologically reliable in determining the hazard potential and the related probability of occurrence $\left(p_{S i}\right)$ by studying, modelling and assessing individual processes and defined design events. To this end, it is worth noting that, whilst in the past the concept of risk was primarily intended as a measure of the probability of a system's failure, it has got, nowadays, in pursuance of equation (1), a more complex meaning. The risk has to be considered as a combination of both the probability and the magnitude of the consequences of a system's failure, 
and so, as the mathematical expectation of the consequence, taking into account of all significant hazards and all significant mechanisms of failure [10].

Therefore, the risk-analysis procedure to be applied to a particular system, should consist of two different and consequential phases: a first phase aimed at clarifying the object of the analysis and at defining the variables on which the risk depends, and a second one aimed at specifying the conditions and the modes of the considered system failure.

So far, little attention has been given to the damage potential affected by hazard processes, particularly concerning spatial patterns and temporal shifts. Studies related to the probability of exposure of an object to a defined scenario and the appropriate vulnerability of the object have predominantly carried out so far as proposal to determine the risk of property and human life with the focus on risk within specific location and specific points in time [2].

\subsection{Risk management cycle}

According to the ISDR [9], the risk management cycle comprises "the systematic process, administrative decisions, organisation, operational skills and abilities to implement policies, strategies and coping capacities of the society and communities to lessen the impact of natural hazards and related environmental and technological disasters". This covers all forms of activities, including structural and non-structural measures to avoid or to limit adverse effects of hazards. On the whole, the risk management approach consists of systemic actions set up in a cycle of preparedness, response and recovery that should form part of any integrated water resource management.

Preparedness consists of preventive and precautionary measures to prepare for an event before it occurs. It aims at minimizing the effect of development activities on accentuating the magnitude of hazards, reducing the exposure to natural hazards and minimising the socio-economic vulnerability of people and material assets exposed to these hazards. Response consists of measures that limit the effects of exposure to a hazard and its duration. It mainly focuses on alerting potential affected people, rescuing victims and providing assistance in case of need. The recovery phase aims at enabling the economic and social activities to return to normal with a minimum delay. It also involves the analysis of the disaster in order to learn lessons and integrate corrective measures into prevention and preparedness plans. To this end, it is important to underline that the effectiveness of the risk management cycle in reducing risks and damages depends, also, on the political will to apply the risk management principles in developing planning, the existence of well defined institutional responsibilities and on a democratic process of consultation and social control with effective governance.

The above principles of risk management should be applied for all risks. Preparedness, response and recovery require a sound knowledge of hazards. The key factors for risk management are time, extent of the impact and coping capacity of the society concerned. The challenge before the international community is to support these activities, particularly in developing countries, where resources are limited, by means of actions aiming at: 
- $\quad$ informing policy makers and the public of the trends in water-related risks and policy options to mitigate those risks;

- introducing long-term water sector planning through integrated water resources management (including risk assessments) and adaptive management to reduce vulnerability to risks;

- raising awareness of water-related hazards and improving the capacity of communities to respond effectively;

- developing conventional and state-of-the-art technologies and monitoring systems tailored to local conditions for water-hazard alerts ;

- $\quad$ fostering specific capacity development programmes for water managers.

\section{Flood and river basin management}

The worldwide damage caused by flooding has been extremely severe in recent decades. No other natural hazard has appeared so frequently, claimed more human lives, generated such economic losses and ruined more fertile land [17]. In the decade from 1986 to 1995, flooding accounted for $31 \%$ of the global economic losses from natural catastrophes and 5.5\% of the causalities [3].

It is assumed that under warmer conditions, due to the effect of climate change, the hydrological cycle will become more intense, stimulating rainfall of greater intensity and longer duration, causing longer periods of flooding and droughts [18]. To cope with such challenges, river basin management policies and flood mitigation measures must be implemented, enabling societies to increase their resilience to flood hazard, while ensuring that development efforts do not increase vulnerability to these hazards [16]. The need for protective measures arises from the frequency and character of flooding and the potential damage to man and the environment.

\subsection{The systemic approach to flooding problems}

The objective of the systemic approach to flooding problems is to develop a set of measures suitable to reduce the damage to an acceptable level and to maximize the efficient use of flood-prone land. To do this, it is necessary to integrate river basin management and flood hazard mitigation strategies into the broader context of catchment management both in terms of land and water management. In choosing between the strategies it is necessary to compare the effectiveness of the options against all the possible flood events.

Notwithstanding all these efforts, at present, there are not sufficient and effective measures globally available to limit the growing chance and consequence of flooding. The evidence is that flood risk is increasing and continuing vigilance is needed to ensure that existing systems are maintained and improvements introduced. To this end, it is imperative that human society adopts the risk management approach herewith outlined, is there is to be harmonious coexistence with floods. In practical terms, the chance of flooding can never be eliminated entirely. However, the consequences of flooding can be mitigated by appropriate measures and actions. As previously underlined, the effects of 
climate change cannot be brought under control. However, suitable actions are both possible and needed to begin to reduce the exposure and vulnerability to flood hazard of people and property and, thereby, enhance flood security.

New, long-term strategies that address flood mitigation and control issues must include measures that are noticeably effective within the fundamental unit of a water management system, i.e. the river basin. To be effective these measures have to be integrated with other aspects, such as socio-economics, culture, nature and the environment. This process has led to the development of the so-called "Room for River and People" concept, which has become recognized as attractive for authorities managing river basins, at least in Western Europe, during the last decade [5]. This concept has led to a substantial impact on the setting-up of suitable measures, with respect to river basin management and flood protection, which are generally categorized as structural and nonstructural [17].

\subsection{Flood protection measures: structural and non-structural}

Structural measures of flood management are measures which alter the physical characteristics of the floods (storage in reservoirs, upstream catchment management, channel modifications, levees/embankments). Non-structural measures are measures which alter the exposure of life and properties to flooding (floodplain land use planning, flood forecasting and warning , flood proofing, evacuation, insurance, etc.) [19]. The first measures aim at reducing the challenge, the second ones enhance the coping capacity.

\subsection{Challenges and developments}

The objective of the systemic approach to flood hazard management is to maximize the efficient use of flood-prone land. To this end, the best solution is to regard the different structural and non-structural measures as complements, rather than as alternatives.

The use of a portfolio of mixed measures is always preferable because of the risk of failure of any single strategy. A fundamental stage of the process of evaluating and choosing a possible portfolio of measure should be an assessment of what will happen when it fails. It is therefore necessary to consider the effect of the whole intervention strategy across the entire spectrum of flood events at the river basin level. As a matter of fact interventions are usually targeted at reducing the impact of frequent floods in a particular area, but the impacts of these interventions on more extreme events must also be considered. The failure of a levee can result in worse flooding than if there had been no levee constructions [13]. Equally, considered across the entire spectrum of possible flood events, those sets of measures which attenuate the effects of floods across the entire spectrum of events are preferable to those which are effectively designed to cope with events of a given return time. Thus, improvements to storage capacity or channel capacity will usually be, in principle, preferable to embankments or levees since, if the channel capacity is increased, then there will be less water out of bank for all possible flood events. Conversely, if an 
embankment fails or is overtopped, the resultant flooding can be more severe than if there was no embankment.

Cost/benefit analysis is a useful way of analysing and comparing the different impacts of flood management options and measures not only in terms of reducing flood losses and increasing productivity, but also in their effects on the environment. In this context, public participation, through catchment management committees, represents a part of paramount importance of the frame concerning not only the selection of management strategies to adopt but also the long-term process of catchment management.

\section{Lessons learnt from flood defence in Europe}

Flood risk management strategies have developed in the past under the influence of both the natural hazards that communities had to cope with and the political behaviour of the societies. Hence, they could be considered as the result of a cultural process. The human perception of floods has changed over time and so has the view on how to react to it.

At present, we witness an increasing urgency to pay attention to flood risk management policy options as worldwide the risk is expected to increase. To this regard, recently UNESCO recognized that "something was wrong" in the old approach to flood risk management, given the increase in numbers of victims and economic damage by floods during the last decades" [15]. It was recognised that floods result in real disasters because of secondary effects, e.g. diseases from poor sanitation. This increase can be only partly attributed to climate change. But more important seems to be the growing populations, especially of urban areas. It was estimated that only $20 \%$ of the increase of flood risk is caused by climate change, whereas demographic and economic developments are responsible for the other $80 \%$ of the increase [12].This recognition brought about a shift, away from control of the flood hazard (structural defence measures) towards managing flood risks through influencing and reducing the vulnerability of the society (non-structural defence measures).

\subsection{The "Room For River And People" concept}

Until recently it was standard policy to raise the crest level of the dikes to maintain the required level of flood protection. This century-old policy was abandoned at the dawn of the new millennium, in favour of the "Room for River and People" approach [15]. This paradigm change was based on the understanding that absolute protection against floods is unachievable. Therefore, the approach to managing flood risks shifted away from only protection to a more holistic risk management process resorting, mainly, to non-structural measures like flood forecasting. early morning and spatial planning. In the new approach to flood management, river cross sections are widened by situating the main dikes further away from the river, or by lowering the river forelands.

This process will lead to lower flood levels and to a new balance between present and foreseeable future spatial requirements for different land uses. Both 
people and water need the resource of floodplains and the new challenge is to design ways of sharing riverine room between floods and people. In practice, this changing view is reflected by the wealth of plans which are being drafted or already implemented in different European states.

\subsection{Examples of flood defence policies}

In UK over the 20th century, three stages can be discerned with regard to the flood management strategies. From the 1930s to about 1970, there was a strong drainage for agricultural tendency, with a policy for flood prevention. From 1970 to the early 1990s economic reasons predominated, leading to a flood defence priority aiming to protect people and property. From the mid 1990s onwards, there has been a gradual shift towards flood risk management, under the influence of an environment movement. This new trend culminated in the Making Space for Water Project carried out in late 2004, to meet the requirements of the "Room for River and People" approach. This project investigated drivers, responses and scenarios for flood risk over a time scale of 100 years. The scenarios took into account different policy frameworks for the country and the project considered flooding from all causes: urban storms, river, estuarine and coastal flooding. The "Making Space for Water" Project set about an integrated portfolio of approaches, which reflect both national and local priorities and highlights the importance of the non-structural measures, in particular of spatial planning, in the context of both the flood risk and water management approaches.

In Germany, because of the federal structure of the country, plans have being made at various levels. There is a Flood Protection Act at the federal level, and there are Water Management Plans in most Länder which address the issue of flood risk at the local (Länder) level. This means that there is no single managing framework responsible for the whole country, and that things may be arranged differently in different Länder, which is the logical consequence of the federal structure.

The Netherlands has a long tradition of flood risk management, which gradually developed towards a flood defence approach in the 1950s. It led to the installation of the so-called Delta Committee and came up with the Delta Plan endorsed by the government. The Delta Plan focused, mainly, on the coast, but in its wake the polders on the flood-prone areas along the large rivers were dealt with similarly. The Plan established varying flood protection levels for different areas of the country, that still represent the design standards for flood protection and prevention in coastal areas and along the major rivers.

During the implementation of the Plan, changes were made in the design of flood defences in accordance with the standards of the "Room for River and People" concept. Factors like the growing awareness of sedimentation processes and of the need to preserve ecological systems and permit commercial navigation led to the "A Different Approach to Water 2000" Act that features the government's position on water management policy in the 21 st century. Important principles in this respect are: greater flexibility in flood and water resources management and a three-step strategy of absorption, storage and 
discharge. Moreover, the Dutch government decided to anticipate climate change and its expected impacts on the environment by 2050 by investing in advance in measures aiming to create more room for the river and remedy potential weaknesses in the coastal defences. Allocation of more space for waters, enhancement of flood defence measures and agreements on terms of actions and responsibilities between the various authorities are essential tools for the success of this policy.

In Italy, in the wake of the floods that plagued the northern part of the Country in the fifties (Polesine, Po valley) and in the sixties (Florence, Arno river catchment), to provide a remedy for the deficiencies in policy and strategy dealing with water-related disasters, a process was set in motion aiming at developing a new integrated approach to water management - at the catchment level and based on the "Room for River and People" concept - suitable to serve as a framework designed to prevent, mitigate, prepare for, respond to and recover from the effects of floods and other water-related disasters. This framework, known as "River Authority", is designed to cope with water management and flood hazard mitigation issues within each of the main Italian catchments.

\subsection{The "Integrated Water Management" approach}

In all European countries where the basic concepts of the "Room for Rivers and People" approach have been adopted, the pattern, whenever possible, was combined with other measures aiming at solving water management problems, such as diffuse source of pollution, contaminated water bodies, water shortages and dropping water-tables. The resulting portfolio of mixed measures is, generally, known as the "Integrated Water Management" approach [14].

This framework allows good opportunities to combine water management with objectives of other policy sectors ,including the reconstruction of rural areas, maintenance of ecological infrastructures, land use, residential construction and development of parks; moreover, it offers a crucial qualitative impulse to the spatial planning for the countries where it is adopted.

Notwithstanding all these advantages, problems may arise due to:

- lack of legislation, with respect to floodplain management. This includes lack of effective enforcement due to misunderstanding of responsibilities between the river manager authorities at various lower levels;

- the undervaluing of maintenance, resulting in budget shortages. This is widespread problem, that can be solved by envisaging medium-term water management plans at both national and catchment levels, with explicit criteria for prioritization;

- the need for innovative project design. Engineers and technicians tend to avoid change and must be reminded to try new methods and techniques;

- contaminated soils, causing public opposition, high costs and long-term mitigating procedures.

The gradual change from the "Flood Risk Management" to the "Room for River and People" and "Integrated Water Management" approaches, that occurred in different European countries, was triggered by a sequel of increasing disasters. Such a change poses many challenges due to its impacts on the 
environment, the society and the economy. To properly cope with these challenges new knowledge is required on flood forecasting, risk computation and methods of spatial planning compatible with flood management. More effort must be put into damage mitigation and flood defence operations. Moreover, the intergenerational timescales for sustainability assessments pose additional questions of how to account for future changes of both the environment and the society and how to handle the uncertainty in the decision-making processes. These assessments need integrated and consistent scenarios for socio-economic developments, global emission and climate and for governance, institutions and values. The UK Flooding Futures projects indicate how this can be approached [12]. Current research in the EC sixth framework Integrated Project is expected to provide concrete innovation on the assessment and management of flood risk within the multi-cultural context of Europe [8].

\section{Concluding remarks}

One-third of the annual natural disasters and economic losses, and more than half of the respective victims are flood related. A burgeoning global population and growing wealth, particularly in the last two or three decades, have increased the risk and the demand for protection from flooding. These features, together with climate change, development pressures and rising public expectations, are changing the way flood risk is managed. These influences are likely to become stronger and accentuate the need to adopt a new approach to living with an increasing threat of flooding.

Flood risk management is a pivotal element of integrated water management and must be based on a catchment approach. This requires international cooperation and an organization that is focused on this system level, with appropriate capabilities and instruments to manage different interest in different locations along the river. So, effective flood risk management depends on adequate harmonization with spatial planning, capable to balance standards and priorities on sustainability, safety and property. Moreover, the process requires cooperation among many partners at the national, regional and local level.

Knowledge and advanced scientific tools play a role of paramount importance in the strain of coping with flooding problems, along with the capacity building in the context of political and administrative frameworks. All these means should be coordinated within an "Integrated Water Management" approach based on the "Room for River and People" concept.

Flood protection is a shared responsibility, according to the old adage "make frameworks to prepare a consistent strategy and avoid ad hoc flood defence initiatives". Therefore, governments need to establish clear institutional, financial and social mechanisms and associated processes for flood risk management, in order to ensure the safety of people and property and, thereby, contribute to flood defence and sustainable development. In this way a harmonious coexistence with floods can be achieved. 


\section{References}

[1] Ang A.H., Tang W.H.: Probability Concepts in Engineering: Emphasis on Applications to Civil and Environmental Engineering, 2nd Edition, 406 pp., Wiley, 2006

[2] Barbolini M., Cappabianca F., Sailes R.,: Empirical estimate of vulnerability relations for use in snow avalanche risk assessment. Risk Analysis IV Brebbia C. (Ed.) Southampton, pp. 533-542, 2004

[3] Borrow F., de Bruin D.: The management of riverine flood risk. Irrigation and Drainage 55. Suppl. 1, pp. 151-157, 2006

[4] Commission of the European Communities: Proposal for a directive of the European Parliament and of the Council on the assessment and management of floods, Brussel, 2006

[5] de Bruin D.: Guest Editor's Editorial Irrigation and Drainage 55, suppl. 1, pp 1-2, 2006

[6] Einstein H.H.: Special lecture: Landslide risk assessment procedure. Int. Symposium on Landslides. In C. Bonnard (Ed.) Landslide vol. 2, pp. 1075 1090, July 1988

[7] El-Cheikh M., Lamb J., Gorst N.: Risk quantitative analysis using fuzzy sets theory. Proceedings of the International Conference of Computational Methods in Science and Engineering, Leiden, pp. 159-162, 2004

[8] Floodsite Consortium: Language of Risk Project: Definitions Report T3204-01, the Hague, 2005

[9] International Strategy for Disaster Reduction (ISDR): Terminology: Basin terms of disaster reduction Updated version, 2004

[10] Meadcroft I.C., Reeve D.E., Allop N.W.H., Diment R.P., Cross J.: Development of new risk assessment procedures for coastal structures. Advances in Coastal Structures and Breakwaters, Thelford T. (Ed.), London, pp. 6-25, 1996

[11] Newson M.: Land Water and Development: River Basin Systems and their Management, Routledge, London, 1992

[12] Office of Science and Technology (OST): Future flooding-executive summary, London, 2004

[13] Penning-Rowsell E.C., Green C.H., Thompson P.M.: The Economics of Coastal Management: A Manual of Assessment Techniques, London, 1992

[14] Rijkswaterstaat A different approach to water policy in the 21st Century, The Hague, 2000

[15] Samuels P., Klijn F., Dijkman J.: An analysis of the current practice of policies on river flood risk management in different Countries Irrigation and Drainage 55, suppl. 1, pp 141-150, 2006

[16] Schultz B.: Irrigation, drainage and flood protection in a rapidly changing world. Irrigation and Drainage 50(4) ,pp. 261-277, 2001

[17] Schultz B.: Flood management under rapid urbanisation and industrialisation in flood-prone areas: A need for serious consideration, Irrigation and Drainage 55, suppl. 1, pp 3-8, 200 
[18] Van Dam J.C. (Ed.) Impacts of Climate Change and Climate Variability on Hydrological Regimes, Cambridge, pp. 140, 1999

[19] van Duivendijk J. Manual on Planning of Structural Approaches to Flood Management. ICID Guideline, New Delhi, 2005

[20] Varnes D.J., and IAEG Commission on Landslides and other Mass Movements and landslide hazard zonation: A review of principles and practice, 63 pp, UNESCO Press, Paris, 1984

[21] Ward R.: Flood: A Geographical Perspective, Macmillian, London, 244 pp, 1978 